\title{
The importance of colonization pressure in multiresistant Acinetobacter baumannii acquisition in a Greek intensive care unit
}

Kostoula Arvaniti ${ }^{*}$, Dimitrios Lathyris ${ }^{2}$, Raymond Ruimy ${ }^{3}$, Anna-Bettina Haidich $^{4}$, Vasiliki Koulourida ${ }^{5}$, Pavlos Nikolaidis ${ }^{6}$, Dimitrios Matamis ${ }^{1}$ and Spiros Miyakis $^{7}$

\begin{abstract}
Introduction: We investigated the role of colonization pressure on multiresistant Acinetobacter baumannii acquisition and defined patient-related predictors for carriage at admission and acquisition during hospitalization in intensive care unit (ICU) patients.

Methods: This was a 12-month, prospective, cohort study of all patients admitted to a single ICU of a tertiary hospital. Screening samples were collected at ICU admission to identify imported carriers, and weekly during hospitalization to identify acquisition. Colonization pressure (carriers' patient-days $\times 100 /$ all patients' patient-days) and the absolute number of carriers were calculated weekly, and the statistical correlation between these parameters and acquisition was explored. Multivariable analysis was performed to identify predictors for $A$. baumannii carriage at admission and acquisition during hospitalization. A. baumannii isolates were genotyped by repetitive-extragenic-palindromic polymerase chain reaction (PCR; rep-PCR).

Results: At ICU admission, 284 patients were screened for carriage. A. baumannii was imported in 16 patients (5.6\%), and acquisition occurred in 32 patients (15.7\%). Acquisition was significantly correlated to weekly colonization pressure (correlation coefficient, $0.379 ; P=0.004$ ) and to the number of carriers per week (correlation coefficient, $0.499 ; P<0.001$ ). More than one carrier per week significantly increased acquisition risk (two to three carriers, odds ratio $(\mathrm{OR}), 12.66 ; P=0.028$; more than four carriers, $\mathrm{OR}, 25.33 ; P=0.004)$. Predictors of carriage at admission were infection at admission (OR, 11.03; confidence interval $(C \mathrm{Cl}, 3.56$ to 34.18 ; $P<0.01)$ and hospitalization days before ICU $(\mathrm{OR}, 1.09 ; \mathrm{Cl}, 1.01$ to $1.16 ; P=0.02)$. Predictors of acquisition were a medical reason for ICU admission (OR, 5.11; Cl, 1.31 to $19.93 ; P=0.02)$, duration of antibiotic administration in the unit $(\mathrm{OR}, 1.24 ; \mathrm{Cl}$, 1.12 to $1.38 ; P<0.001)$, and duration of mechanical ventilation $(\mathrm{OR}, 1.08 ; \mathrm{Cl}, 1.04$ to $1.13 ; P=0.001)$. All strains were multiresistant. Rep-PCR analysis showed one dominant cluster.
\end{abstract}

Conclusions: Acquisition of multiresistant A. baumannii in ICU patients is strongly correlated to colonization pressure. High levels of colonization pressure and more than two carriers per week independently increase acquisition risk. Patient-related factors, such as infection at admission and long hospitalization before the ICU, can identify imported A. baumannii carriers. Medical patients with extended administration of antibiotics and long duration of mechanical ventilation in the ICU were the most vulnerable to acquisition.

\footnotetext{
* Correspondence: arvanitik@hotmail.com

'Intensive Care Unit, "Papageorgiou" General Hospital, Periferiaki Odos,

Thessaloniki, 56403, Greece

Full list of author information is available at the end of the article
} 


\section{Introduction}

Acinetobacter baumannii has become a troublesome emerging pathogen because of its wide range of resistance determinants and its environmental resilience $[1,2]$. It is responsible for severe nosocomial infections in intensive care unit (ICU) patients, mainly ventilatorassociated pneumonia (VAP), bacteremia, and central nervous system infections [1,3-6]. Most of A. baumannii strains are resistant to major antimicrobial drugs (multidrug-resistant (MDRs)) [1,7,8]. MDR strains have become endemic in several health care environments and often cause sustained outbreaks [1,9-12]. Infected and colonized patients (carriers) represent major reservoirs for horizontal transmission and spread in nosocomial environment, through the hands of healthcare personnel [1,11-15].

Acquisition of MDR bacteria in an ICU depends on ICU-related variables (nurse-to-patient ratios, compliance with hand hygiene) and patient-related factors (severity of illness, prior hospitalization, invasive procedures, antibiotic use) [13-18]. Colonization pressure created by carriers (or colonized patients) has been indicated as a contributing factor for acquisition of MDR bacteria (methicillin-resistant Staphylococcus aureus (MRSA) and vancomycin-resistant Enterococcus sp. (VRE)) $[19,20]$, but not yet extensively for A. baumannii $[17,21]$.

Our hypothesis was that the acquisition of multiresistant $A$. baumannii in the ICU setting is strongly related to high levels of colonization pressure and to patientrelated factors. To determine the role of these factors, we studied the effect of colonization pressure, nurse-topatient ratios, severity, duration of invasive procedures, and use of antibiotics on A. baumannii acquisition. Additionally, we searched for predictors of carriage at ICU admission, such as comorbidities, severity and type of illness, prior hospitalization, and antibiotic use, assuming that they can help physicians promptly identify imported reservoirs of the pathogen.

\section{Materials and methods}

The study was conducted in a general (medical, surgical, and trauma) adult, 15-bed ICU of a 750-bed, tertiarycare, university-affiliated hospital in Thessaloniki, Greece. The ICU had two subunits, one with 10 beds and another with five beds. Subunits had only two-bed rooms. Each nurse was responsible for two to three patients and had 8-hour shifts. Six physicians and five physicians-in-training worked in the unit every day.

Standard hygiene precautions [22] were applied. Hand antisepsis with alcohol hand rubs, before and after each contact with a patient and the surrounding surfaces, was implemented. Screening sampling at ICU admission and on a weekly basis was performed for A. baumannii and MRSA. Contact isolation precautions with protective gowns and gloves were applied for proven cases of carriage or infection with $A$. baumannii or MRSA, as well as for patients infected with carbapenem-resistant Pseudomonas aeruginosa or Klebsiella pneumoniae [23]. For all those patients, confinement (isolation) was not performed, because the unit was composed of two-bed rooms, whereas nurse cohorting was implemented when daily nurse-to-patient ratios were below or equal to 1:2. For patients transferred from other institutions or other ICUs, contact precautions were applied until results of screening samples were collected at ICU admission. Chlorhexidine was used for daily body washing of patients.

Hand-hygiene compliance was not monitored. Educational meetings were being held every 3 months to emphasize the importance of hand hygiene and contact precautions to ICU staff and to provide essential feedback. Infection-control policy included continuous surveillance of nosocomial infections and was revised yearly by an ICU physician specialized in infectious diseases and the Institute's Infection Control Committee. Nosocomial infections in the ICU (that is, infections occurring after the first 48 hours in the unit) were evaluated according to CDC/NHSN definitions [24,25]. Antibiotic treatment was based on epidemiologic data and guidelines for each type of infection [26-30]. No selective digestive decontamination or antibiotic rotation was performed. Deescalation was routinely effectuated after culture results $[31,32]$. The most common empiric antibiotic regimen in case of clinical suspicion of severe nosocomial sepsis was imipenem for the coverage of $A$. baumannii and $P$. aeruginosa. An antibiotic with activity against MRSA was initially prescribed in case of septic shock, presence of a prosthetic endovascular or an orthopedic device, transfer from wards with a high prevalence of MRSA, or hospitalization in the ICU of more than one patient with MRSApositive samples (screening or clinical samples).

This was a prospective cohort study that included all consecutive patients admitted into the unit between August 2008 and July 2009. Only the first ICU admission per patient was included in the analysis. Patients were evaluated for (a) carriage at admission and (b) acquisition during hospitalization. Patients without screening samples at admission were excluded. Imported carriers and those without follow-up samples (due to discharge or death before the scheduled follow-up sampling) were excluded from acquisition analysis. Only the initial isolate from each patient was counted and underwent molecular typing.

The study was approved by the Institute's Ethics committee. No written consent was obtained from patients, 
because no therapeutic intervention was undertaken; carrier screening was part of the routine practice in the unit; and all data were anonymous.

\section{Data collection}

Demographic data, underlying diseases, severity scores, invasive procedures, antibiotic use, weekly nurse-topatient ratios, and weekly levels of colonization pressure were collected prospectively by using a standard written questionnaire. The accuracy and completion of each questionnaire was evaluated every week by two participating authors.

More specifically, the following data were collected: age, sex, date of hospital and ICU admission, diagnosis on ICU admission, comorbidities, McCabe score, immunodeficiency (hematologic malignancy, metastatic cancer, AIDS, immunosuppressive therapy or chemotherapy, corticosteroids (daily dose $\geq 1 \mathrm{mg} / \mathrm{kg}$ of prednisolone for 1 month or any daily dose for $>1$ month), neutropenia), Acute Physiology and Chronic Health Evaluation-APACHE II, Simplified Acute Physiologic Score-SAPS II, and Organ Dysfunction, and/or Infection-ODIN on ICU admission, length of ICU stay, and ICU outcome (death or not)) [33-36]. Imported and acquired cases and time to A. baumannii acquisition were recorded. During ICU hospitalization, duration of antibiotic administration, of invasive procedures (mechanical ventilation (MV), central venous (CVC) and arterial catheterization, enteral feeding tube, urinary tract catheterization) and duration of propofol infusion were recorded in the questionnaire.

The unit of time chosen for measurements was the week (from Monday through Sunday). Nurse-to-patient ratios (N/P) per week were monitored, and weekly colonization pressure created by all (imported and acquired) A. baumannii carriers was calculated, as described by Merrer et al. [20]:

$$
\begin{gathered}
\begin{array}{c}
\text { number of }(\text { admitted }+ \text { acquired }) \text { carriers' patient }- \text { days in } \\
\text { the week before acquisition } \times 100
\end{array} \\
\text { total number of patient }- \text { days in the week before } \\
\text { acquisition }
\end{gathered}
$$

Samples for carriage were collected with cotton swabs (Transwab for aerobic and anaerobic; Medical Wire and Equipment Ltd., Corsham, England) from pharynx, skin, and rectum (screening samples), at ICU admission (initial sample, that is, within the first 48 hours of admission) and afterward on a weekly basis (every Monday), (follow-up samples) until discharge or death. Swabs were processed in specific media, as previously described [37]. Identification, confirmation, and susceptibility testing were performed with the Wider automated system, according to the National Committee for Clinical Laboratory Standards (NCCLS) criteria and breakpoints [38]. Microbiologic data including cultures and antibiotic susceptibility tests of screening samples were interpreted by a senior microbiologist on a daily schedule. All isolates were kept at $-35^{\circ} \mathrm{C}$ for molecular analysis, which was effectuated and interpreted blindly by a senior specialized microbiologist, after completion of all other data collection. Bacteria from the frozen stock were inoculated onto Muller-Hinton agar (SanofiPasteur, Marne la Coquette, France). PCR amplification of repetitive extragenic palindromic sequences (RepPCR) was performed for unique isolates by using the primers and the protocol described by Snelling et al. [39].

\section{Definitions}

A patient was considered a carrier if he or she had at least one positive screening sample. Carriage at ICU admission (imported carriage) and acquisition during hospitalization in the unit (acquired carriage) were defined as isolation of $A$. baumannii from at least one screening sample obtained within or later than the first 48 hours of admission, respectively. Imported carriers were considered to be carriers throughout their entire stay, and acquired carriers were considered to be carriers from the date of the first positive sample until discharge or death. An infection was considered to be present at ICU admission if it was diagnosed within the first 48 hours in the unit. Multiresistance was defined as resistance to more than two of the following five drug classes: antipseudomonal cephalosporins (ceftazidime or cefepime), antipseudomonal carbapenems (imipenem or meropenem), ampicillin-sulbactam, fluoroquinolones (ciprofloxacin or levofloxacin), and aminoglycosides (gentamicin, tobramycin, or amikacin) [1].

\section{Statistical analyses}

Descriptive analysis of the data was performed. Continuous variables were presented as median (interquartile range [IQR]) values, as they were not normally distributed (if not, mean $\pm \mathrm{SD}$ was added), and categoric variables, as counts and percentages. Logistic regression analyses were performed to assess predictors of $A$. baumannii carriage at (a) admission and (b) acquisition during hospitalization. All variables with a $P$ value less than 0.05 in univariable analysis were included in a logistic regression model for multivariable analysis. To preserve the sufficient events per variable, from the significant univariable parameters, all possible two-variable models were determined for imported A. baumannii carriers $(n=16)$ and all possible three-variable models were determined for acquired carriers $(n=32)$. The selection of the final multivariable model presented was the one with the better fit in terms of deviance, the one with the smallest -2-log likelihood. 
Also, the goodness of fit was evaluated with the HosmerLemeshow test, in which an insignificant result indicated a good fit [40]. Predictor variables that were highly correlated were not entered together in the model to preserve for collinearity problems. Odds ratios were presented with the corresponding 95\% confidence intervals (OR, CI 95\%). Correlation between acquisition and weekly values of parameters (colonization pressure, total $A$. baumannii carriers, and nurse-to-patient ratio) was calculated by using the Pearson correlation coefficient. OR and 95\% CI were used to evaluate the risk for acquisition at different numbers of total A. baumannii carriers hospitalized per week in the ICU.

The Rep-PCR patterns were analyzed by using the Bionumerics software (V1.5; Applied Maths, Ghent, Belgium) in a blind fashion (that is, without knowledge of the clinical data). Distance matrices were determined by using the Pearson correlation coefficient, and dendrograms were created by using the unweighted pair group method with arithmetic averages (UPGMA).

All tests were two-sided, and a $P$ value less than 0.05 was considered statistically significant in the multivariable analyses. The analyses were conducted by using PASW Statistics (version 18; SPSS, Chicago, IL, USA).

\section{Results}

During the study period, 301 patients were admitted in the ICU and assessed for eligibility. Forty-five (15\%) patients had an infection at ICU admission; 120 (40\%) had received previously antibiotics, and 168 (56\%) were hospitalized in the preceding 12 months. For 185 (61\%) patients, the main reason for ICU admission was medical; $126(42 \%)$ patients were transferred from the emergency department; 143 (50\%) from other hospital wards; and $15(5 \%)$ from ICUs of other institutions. Seventy-six (25\%) patients died in the ICU.

Seventeen (5.6\%) patients 301 were excluded from analysis for A. baumannii carrier status because sampling was not performed (four died in less than 2 hours; for eight patients, the sampling was neglected, and five patients were readmitted). Finally, 284 (94.3\%) of 301 patients were evaluated for $A$. baumannii carriage (screened population).

Sixteen $(5.6 \%)$ of 284 patients were imported carriers at ICU admission and were excluded from acquisition analysis. Two hundred sixty-eight (94.4\%) of 284 patients were evaluated for A. baumannii acquisition. Of these, 64 (23.9\%) patients were excluded, as they had no follow-up sample (48 were discharged, and 16 died before the scheduled sampling).

Finally, 204 (76\%) patients were evaluated for A. baumannii acquisition. Thirty-two (15.7\%) of 204 patients acquired A. baumannii in the ICU after a delay of a median 12 days (IQR, 10 to 17.5) (Figure 1).
The pharynx was the most frequent isolation site for both imported (11 of 16, 69\%) and acquired (19 of 32, $59 \%)$ carriers. Skin carriage was identified in four $(25 \%)$ of 16 imported and nine (28\%) of 32 acquired carriers, whereas the rectum was found to be positive in only one $(6 \%)$ of 16 imported and four (13\%) of 32 acquired carriers.

The median calculated weekly colonization pressure was $25.6 \%$ (IQR, 9.3 to 47.8 ) and ranged from 0 to $96 \%$. During 28 ( $54 \%$ of the study period) of 52 study weeks, colonization pressure exceeded the median value. The median number of all $A$. baumannii carriers per week was 3.5 (IQR, 1 to7) and during 30 (58\% of the study period) of 52 study weeks, more than 3.5 carriers were concomitantly hospitalized in the unit. The mean value $( \pm \mathrm{SD})$ of the weekly nurse-to-patient ratio was 1:2.7 ( \pm 0.3 ) (range, 1:1.8 to 1:3.3) and median 1:2.7 (IQR, 1:2.5 to $1: 2.7$ ), whereas, for 19 (36.5\% of the study period) of 52 weeks, ratios were below these values. Weekly colonization pressure (correlation coefficient, $0.379 ; P=$ 0.004 ) and total number of $A$. baumannii carriers per week (correlation coefficient, 0.499; $P=0.0001$ ) were significantly associated with $A$. baumannii acquisition, but not the nurse-to-patient ratio (correlation coefficient, $-0.064 ; P=0.064$ ). The presence of more than one A. baumannii carrier in the unit per week, either imported or acquired, strongly predicted increased acquisition risk (two to three carriers per week, OR, 12.66; $P=0.028$; and more than four carriers, $O R$, 25.33; $P=0.004)$.

ODIN score, infection at ICU admission, hospitalization before ICU admission, hospital days before ICU admission, and antibiotic administration before ICU admission were identified as risk factors for imported carriage in univariable analysis (Table 1). A medical reason for ICU admission, ICU days before acquisition, antibiotic and propofol administration in the unit, days of antibiotics and propofol use in the unit, and duration of invasive procedures (mechanical ventilation, enteral tube feeding, $\mathrm{CVC}$, arterial and urinary tract catheterization) were associated with acquisition in univariable analysis (Table 2).

Infection at ICU admission (OR, 11.03; 95\% CI, 3.56 to $34.18 ; P<0.01$ ) and duration of prior hospitalization were independently associated with carriage at admission in multivariable analysis (OR, 1.09; 95\% CI, 1.01 to 1.16; $P=0.02$ ) (Table 3). Hospitalization before ICU admission and hospital days before ICU were not entered together in the logistic regression models because of collinearity.

In multivariable analysis for the acquisition, medical reason for ICU admission (OR, 5.11; CI, 1.31 to 19.93; $P$ $=0.02)$, antibiotic days in the ICU $(\mathrm{OR}, 1.24 ; \mathrm{CI}, 1.12$ to 1.38; $P<0.001)$, and mechanical ventilation days (OR, 


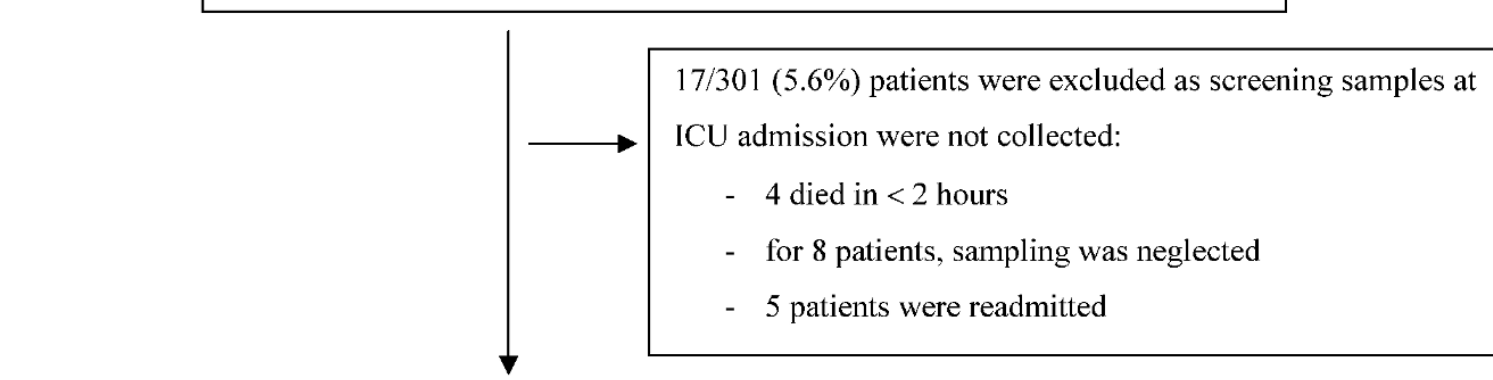

284/301 (94\%) patients were screened for carriage at ICU admission and were included in the analysis for $A$. baumannii carriage (screened population)

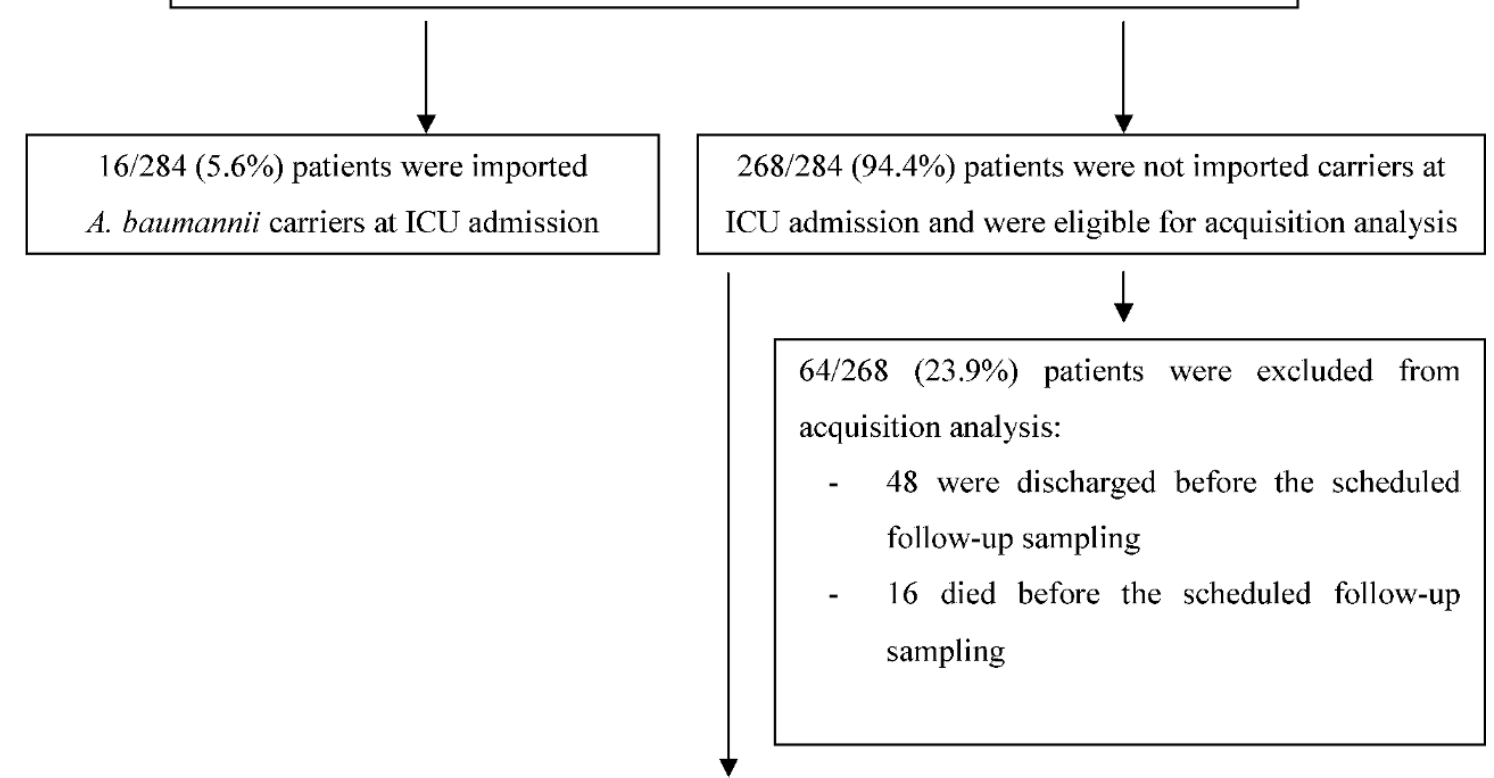

204/268 (76.1\%) patients were included in acquisition analysis

32/204 (15.7\%) patients acquired A. baumannii during ICU hospitalization
$172 / 204(84.3 \%)$ patients did not acquire

A. baumannii carriage during ICU hospitalization

Figure 1 Flow chart of the patients

1.08; CI, 1.04 to $1.13 ; P=0.001)$ were found to be significant risk factors (Table 3 ). The following factors were not analyzed in the multivariable analysis for acquisition: duration of enteral tube feeding, and of arterial and urinary tract catheterization due to collinearity with duration of mechanical ventilation. Antibiotic use and mechanical ventilation before acquisition were excluded, as they were found in all acquired carriers. Propofol use, as a categoric variable, was not analyzed in the acquisition multivariable analysis 
Table 1 Univariable analysis of risk factors for multiresistant Acetinobacter baumannii carriage at ICU admission

\begin{tabular}{|c|c|c|c|c|}
\hline Variable & & & $\begin{array}{l}\text { Univariable } \\
\text { analysis }\end{array}$ & \\
\hline & $\begin{array}{l}\text { A. baumannii carriers at ICU admission } \\
(n=16)\end{array}$ & $\begin{array}{l}\text { Noncarriers at ICU admission ( } n \\
=268)\end{array}$ & OR $(95 \% \mathrm{Cl})$ & $\begin{array}{l}P \\
\text { value }\end{array}$ \\
\hline Age, median [IQR] & $67.5[38-73.5]$ & $64[41-72]$ & $1(0.98-1.03)$ & 0.77 \\
\hline Males $n(\%)$ & $13(81)$ & $173(65)$ & $2.38(0.66-8.56)$ & 0.18 \\
\hline APACHE II, median [IQR] & $21[15.1-26]$ & 17 [13-23] & $1.04(0.98-1.09)$ & 0.19 \\
\hline SAPS II, median [IQR] & $50.5[40-64.2]$ & $41[28-54]$ & $1.02(0.99-1.04)$ & 0.15 \\
\hline ODIN, median [IQR] & $3[2.25-4]$ & $2[1-3]$ & $1.50(1.04-2.15)$ & 0.03 \\
\hline \multicolumn{5}{|l|}{ McCabe $n(\%)$} \\
\hline $0-1$ & $9(56)$ & $173(59.7)$ & $0.70(0.26-1.95)$ & 0.50 \\
\hline $2-3$ & $7(44)$ & $95(32.8)$ & & \\
\hline \multicolumn{5}{|l|}{ Reason for ICU admission $n(\%)$} \\
\hline Medical reason & $11(68.7)$ & $174(64.9)$ & $1.189(0.4-3.52)$ & 0.75 \\
\hline Surgery before ICU admission & $5(31)$ & $94(36)$ & & \\
\hline Trauma & $2(12.5)$ & $51(19)$ & $0.60(0.13-2.76)$ & 0.52 \\
\hline Infection at ICU admission & $10(63)$ & $37(14)$ & $10.41(3.57-30.34)$ & 0.001 \\
\hline \multicolumn{5}{|l|}{ Main reason for ICU admission $n(\%)$} \\
\hline Other & $3(18.75)$ & $68(25.4)$ & 1 & \\
\hline Acute respiratory failure & $6(38)$ & $64(24)$ & $1.32(0.34-5.10)$ & 0.69 \\
\hline Neurologic disorder & $6(38)$ & $107(40)$ & $0.94(0.26-3.42)$ & 0.93 \\
\hline Hemodynamic disorder & $1(6.25)$ & $29(11)$ & $0.58(0.06-5.35)$ & 0.63 \\
\hline $\begin{array}{l}\text { Hospitalization before ICU admission } n \\
(\%)\end{array}$ & $14(87.6)$ & $144(53.7)$ & $5.18(1.15-23.2)$ & 0.03 \\
\hline In ward & $11 / 14(78.5)$ & $132 / 144(91.7)$ & & \\
\hline In another ICU & 3/14 (21.4) & 12/144 (8.3) & & \\
\hline $\begin{array}{l}\text { Hospital days before ICU admission, } \\
\text { median [IQR] }\end{array}$ & $5[2.25-12.25]$ & $0[0-4]$ & $1.08(1.02-1.13)$ & 0.005 \\
\hline $\begin{array}{l}\text { Antibiotic use before ICU admission } n \\
(\%)\end{array}$ & $15(94)$ & $105(39)$ & $23.29(3.03-178.7)$ & 0.002 \\
\hline
\end{tabular}

APACHE II, Acute Physiologic And Chronic Health Evaluation; CVC, central venous catheter; ICU, intensive care unit; IQR, interquartile range; ODIN, Organ Dysfunctions and/or Infection; OR, odds ratio; Other, postsurgery follow-up, trauma, cancer, and immunodeficiency; SAPS II, Simplified Acute Physiology Score II.

because of clinical criteria. Although it was clearly used in fewer acquired carriers than in nonacquired ones, we considered that this result was found by chance, as our study was not randomized, and propofol cannot be considered a protective factor (OR, 0.188 ; CI, 0.085 to 0.417; $P<0.001$ ) for multiresistant $A$. baumannii acquisition. Duration of mechanical ventilation and of CVC catheterization was not analyzed in the same logistic regression model because of collinearity. When mechanical ventilation days were replaced in the regression model by CVC days, similar results were obtained, but the model that contained the duration of mechanical ventilation had a better fit (-2 log likelihood, 132.4), than did the one with duration of $\mathrm{CVC}$ catheterization (-2 log likelihood, 140.4).

\section{Microbiologic results}

All isolates were multiresistant (Table 4). Nonsusceptibility to imipenem was noted in $6(37.5 \%)$ of 16 imported and $15(46.8 \%)$ of 32 acquired isolates.
Nonsusceptibility to colistin was rarely found (6\%), and this was exclusively among acquired isolates. High rates of nonsusceptibility to other antimicrobials were recorded. All recovered A. baumannii isolates were genotyped. Rep-PCR patterns revealed clusters of isolates (Figure 2 dendrogram). Among imported strains, 10 $(62.5 \%)$ of 16 belonged to cluster III, and six (37.5\%) of 16 to clusters I, II, and V. Among the 32 acquired strains, 23 (72\%) belonged to cluster III, and nine (28\%), to cluster II.

\section{Discussion}

This prospective cohort study, performed in a general ICU with severely ill patients, demonstrated the impact of colonization pressure and patient-related variables (medical reason for ICU admissions, antibiotic exposure, and invasive procedures) on multiresistant $A$. baumannii acquisition during ICU hospitalization and identified predictors of multiresistant $A$. baumannii carriage at ICU admission. 
Table 2 Univariable analysis of risk factors for multiresistant Acetinobacter baumannii acquisition during ICU hospitalization

\begin{tabular}{|c|c|c|c|c|}
\hline \multirow[t]{2}{*}{ Variable } & \multirow[b]{2}{*}{$\begin{array}{l}\text { Patients with } A \text {. Baumannii } \\
\text { acquisition }(n=32)\end{array}$} & \multirow[b]{2}{*}{$\begin{array}{l}\text { Patients without } A \text {. baumannii } \\
\text { acquisition }(n=172)\end{array}$} & \multicolumn{2}{|l|}{$\begin{array}{l}\text { Univariable } \\
\text { analysis }\end{array}$} \\
\hline & & & OR $(95 \% \mathrm{Cl})$ & $\begin{array}{l}P \\
\text { value }\end{array}$ \\
\hline Age, median [IQR] & $51(32-69)$ & $63(40.25-72)$ & $0.98(0.97-1.003)$ & 0.10 \\
\hline Males $n(\%)$ & $24(75)$ & $108(63)$ & $1.78(0.75-4.19)$ & 0.19 \\
\hline APACHE II, median [IQR] & $17(13-22)$ & $17(13-22.75)$ & $0.98(0.93-1.03)$ & 0.39 \\
\hline SAPS II, median [IQR] & $40(27.2-52)$ & $41(29-53)$ & $0.99(0.97-1.01)$ & 0.31 \\
\hline ODIN, median [IQR] & $2(1.25-3)$ & $2(1-3)$ & $1.03(0.76-1.38)$ & 0.86 \\
\hline \multicolumn{5}{|l|}{ Mc Cabe $n(\%)$} \\
\hline $0-1$ & $25(75)$ & $109(63)$ & $2.06(0.85-5.05)$ & 0.11 \\
\hline $2-3$ & $7(25)$ & $63(37)$ & & \\
\hline \multicolumn{5}{|l|}{ Reason for ICU admission $n(\%)$} \\
\hline $\begin{array}{l}\text { Medical reason for ICU } \\
\text { admission }\end{array}$ & $28(88)$ & $110(64)$ & $3.85(1.29-11.48)$ & 0.016 \\
\hline Surgery before ICU admission & $4(12)$ & $62(36)$ & & \\
\hline Trauma & $11(34)$ & $33(19)$ & $2.2(0.97-5.02)$ & 0.06 \\
\hline Infection at ICU admission & $6(19)$ & $23(20)$ & $1.49(0.57-4.02)$ & 0.43 \\
\hline \multicolumn{5}{|l|}{ Main reason for ICU admission $n(\%)$} \\
\hline Other & $6(18.7)$ & $42(24.4)$ & & \\
\hline Acute respiratory failure & $9(28)$ & $46(27)$ & $0.73(0.24-2.22)$ & 0.58 \\
\hline Neurologic disorder & $15(47)$ & $66(38)$ & $0.63(0.22-1.75)$ & 0.37 \\
\hline Hemodynamic disorder & $2(6)$ & $18(15)$ & $1.28(0.23-6.99)$ & 0.77 \\
\hline $\begin{array}{l}\text { ICU days before acquisition, median } \\
\text { [IQR] }\end{array}$ & $11.5(9-18.75)$ & $5(3-10)$ & $1.03(1.01-1.06)$ & 0.025 \\
\hline Antibiotic use before acquisition $n(\%)$ & $32(100)$ & $127(74)$ & $10.98(1.46-82.8)$ & 0.02 \\
\hline $\begin{array}{l}\text { Days of antibiotics median } \\
\text { [IQR] }\end{array}$ & $7(5-9.75)$ & $3(0-5)$ & $1.28(1.15-1.42)$ & $\begin{array}{l}< \\
0.001\end{array}$ \\
\hline $\begin{array}{l}\text { Mechanical ventilation before acquisition } \\
n(\%)\end{array}$ & $32(100)$ & $152(88)$ & $4.08(0.53-31.5)$ & 0.18 \\
\hline $\begin{array}{l}\text { Days of mechanical ventilation, } \\
\text { median [IQR] }\end{array}$ & $11.5(8.25-16)$ & $4(2-8)$ & $1.09(1.05-1.14)$ & $\begin{array}{l}< \\
0.001\end{array}$ \\
\hline CVC in the ICU before acquisition $n(\%)$ & $26(81)$ & $152(88)$ & $\begin{array}{l}0.57(0.209- \\
1.554)\end{array}$ & 0.27 \\
\hline Days of CVC, median [IQR] & $12(9-15.7)$ & $6(3-10)$ & $1.07(1.03-1.12)$ & 0.001 \\
\hline Propofol use before acquisition $n(\%)$ & $12(38)$ & $131(76)$ & $0.19(0.09-0.42)$ & $\begin{array}{l}< \\
0.001\end{array}$ \\
\hline Days of propofol, median [IQR] & $5(3.75-7)$ & $2(1-3)$ & $1.20(1.07-1.36)$ & 0.003 \\
\hline Arterial catheter before acquisition $n(\%)$ & $20(63)$ & $154(89.5)$ & $2.06(0.95-4.69)$ & 0.07 \\
\hline Days of arterial catheter, median [IQR] & $11(8-14.7)$ & $6(3-9)$ & $1.07(1.02-1.13)$ & 0.003 \\
\hline $\begin{array}{l}\text { Enteral feeding catheter before } \\
\text { acquisition } n(\%)\end{array}$ & $31(97)$ & $155(90)$ & $1.48(0.64-3.39)$ & 0.36 \\
\hline $\begin{array}{l}\text { Days of enteral feeding tube, median } \\
\text { [IQR] }\end{array}$ & $12(9.2-19)$ & $4(3-9)$ & $1.07(1.04-1.10)$ & $\begin{array}{l}< \\
0.001\end{array}$ \\
\hline Urinary catheter before acquisition $n(\%)$ & $32(100)$ & $165(96)$ & $2.53(0.32-20.08)$ & 0.38 \\
\hline $\begin{array}{l}\text { Days of urinary tract catheterization, } \\
\text { median [IQR] }\end{array}$ & $12.5(9-18.25)$ & $6(3-11)$ & $1.07(1.04-1.10)$ & $\begin{array}{l}< \\
0.001\end{array}$ \\
\hline
\end{tabular}

APACHE II, Acute Physiologic And Chronic Health Evaluation; Cl, confidence interval; CVC, central venous catheter; ICU, intensive care unit; IQR, interquartile range; ODIN, Organ Dysfunctions and/or Infection; OR, odds ratio; other, postsurgery follow-up, trauma, cancer, and immunodeficiency; SAPS II, Simplified Acute Physiology Score II.

The present study is the first to correlate A. baumannii acquisition with colonization pressure, signifying the important role of this parameter in ICU setting. The study also showed that the absolute number of all (imported and acquired) multiresistant A. baumannii carriers hospitalized in an ICU during a specific period (a week), could be related to the increased likelihood for new $A$. baumannii acquisitions. Previous studies already 
Table 3 Multivariable analysis for multiresistant Acetinobacter baumannii carriage at ICU admission and acquisition during hospitalization

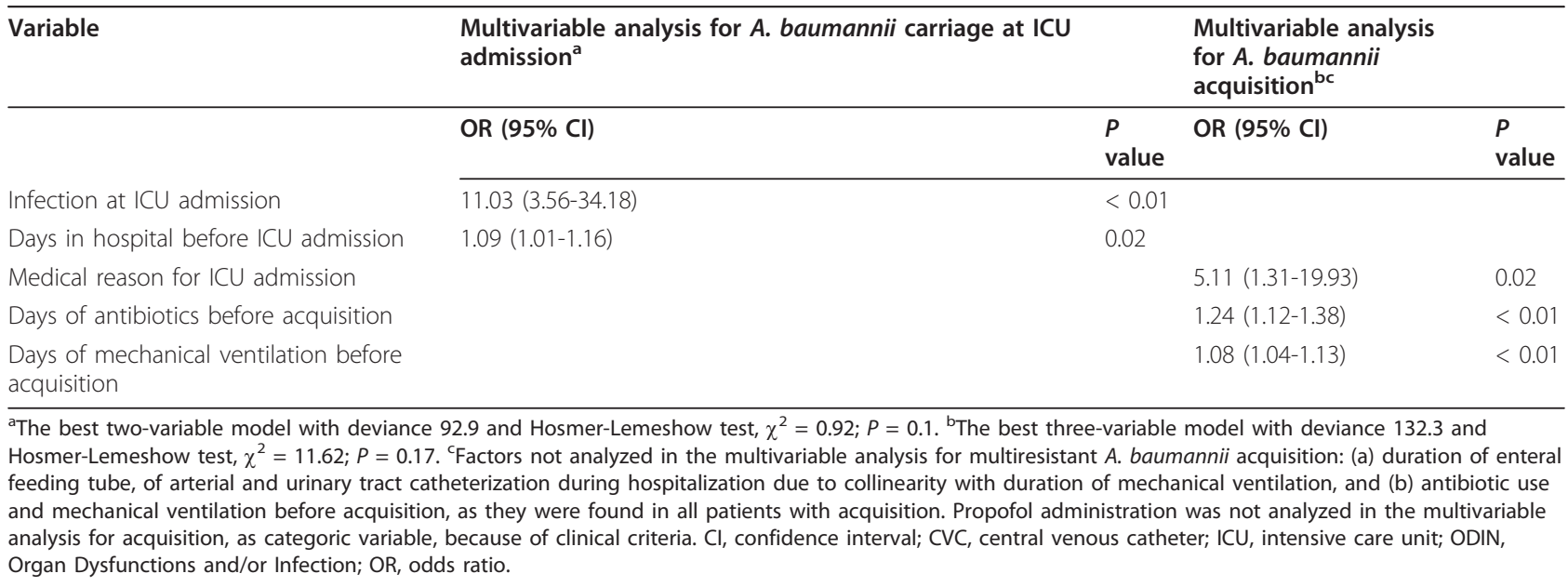

presented similar results for VRE and MRSA [19,20], probably because of the same transmission mode, mainly via contacts with the hands of personnel. Two other trials supported the influence of a high density of A. baumannii infections on dissemination of the pathogen, especially during outbreaks of carbapenem-resistant strains [21,41]. For carbapenem-resistant K. pneumoniae, a direct relation between colonization pressure and nosocomial acquisition of the pathogen also was demonstrated [42].

Absence of correlation between acquisition and nurseto-patient ratios in the current study certainly does not underestimate the influence of understaffing and overcrowding on multiresistant $A$. baumannii acquisition in ICUs, already shown by others $[21,43,44]$. However, in settings with a high incidence of MDR bacteria, colonization pressure could be considered more sensitive than staff ratios or patient-related variables and should be used to alert health care personnel of increased multiresistant A. baumannii acquisition risk $[19,20]$.

Multiresistant $A$. baumannii carriers represented an essential reservoir of the pathogen in the unit. Imported carriers as initial sources and acquired carriers as secondary sources of the pathogen generated a constant colonization pressure that facilitated new acquisitions in the ICU. Each A. baumannii carrier considerably increased the acquisition risk for other patients. During the study period, cross-transmission probably occurred because of lapses in infection-control measures (hand hygiene, contact precautions) in repeated circumstances with high levels of colonization pressure. The architectural design of the unit (only two-bed rooms available) precluded patient isolation, which could possibly help reduce $A$. baumannii dissemination. High patient-

Table 4 Nonsusceptibility of Acetinobacter baumannii isolates to antibiotics

\begin{tabular}{|c|c|c|}
\hline \multirow[t]{2}{*}{ Antibiotic } & Imported A. baumannii isolates & Acquired $A$. baumannii isolates \\
\hline & $\mathrm{I}+\mathrm{R} \%$ & $\mathrm{I}+\mathrm{R} \%$ \\
\hline Piperacillin/tazobactam & 81 & 94 \\
\hline Ceftazidime & 94 & 91 \\
\hline Cefepime & 94 & 88 \\
\hline Gentamicin & 94 & 100 \\
\hline Amikacin & 94 & 91 \\
\hline Tobramycin & 88 & 100 \\
\hline Aztreonam & 94 & 100 \\
\hline Ciprofloxacin & 88 & 100 \\
\hline Imipenem & 38 & 47 \\
\hline Meropenem & 63 & 59 \\
\hline Cotrimoxazole & 88 & 91 \\
\hline Colistin & 0 & 6 \\
\hline
\end{tabular}

$\mathrm{I}$, intermediate; $\mathrm{R}$, resistant. 


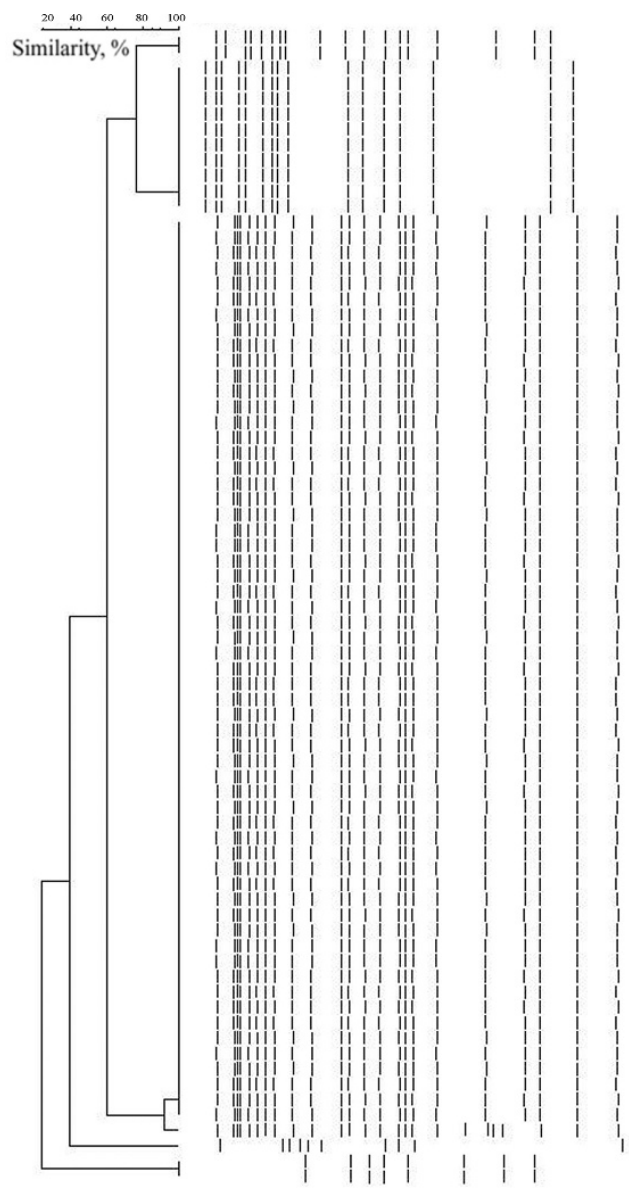

Figure 2 Dendrogram illustrating genetic diversity among multiresistant $A$. baumannii strains. Molecular analysis revealed one predominant cluster (III) of $A$. baumannii isolates among other minor ones $(I, I I, V)$. Cluster III included study isolates $A_{1-2-3-5-6,}, B_{2-5-7,}$ $C_{1-2-5-6-7}, D_{2-3-4-5-6,}, E_{6-7-8}, F_{1-2-4-5-6}$, and $G_{1-2-4-6-7-8}$. Ten (62.5\%) of 16 imported strains and $23(72 \%)$ of 32 acquired strains belonged to cluster III.

severity scores, prior hospitalization, and prolonged exposure to invasive procedures and antibiotics increased, for each ICU patient that was previously exposed to high levels of colonization pressure, the probability of acquiring one of the circulating clusters.

Imported A. baumannii carriers were admitted in the unit from other hospital wards or other ICUs in town, demonstrating dissemination in the entire hospital and implying interinstitutional or even regional transmission of the pathogen [1,9-12].

In accordance with other reports, we found that duration of hospitalization before ICU admission was independently associated with imported carriage $[16,45]$. For each previous day in hospital, the risk of $A$. baumannii carriage at ICU admission increased by $8 \%(P=0.034)$.

Prior antibiotic use and duration of antibiotic exposure had already been identified as predictors of acquisition of MDR bacteria containing specific resistance mechanisms $[19,46,47]$. Nevertheless, direct association between duration of antibiotic administration and multiresistant $A$. baumannii acquisition in the ICU, as shown in the study, was not previously recognized.

Medical patients and patients with longer duration of mechanical ventilation were at higher risk of acquiring multiresistant $A$. baumannii during their ICU stay. For medical patients, this could be attributed to underlying comorbidities; however, this hypothesis can be neither adopted nor rejected by the current study. Duration of mechanical ventilation or CVC catheterization has already been described as a risk factor for A. baumannii acquisition $[48,49]$.

Molecular analysis revealed one predominant cluster of $A$. baumannii isolates among other minor ones, probably reflecting endemicity and cross-transmission [50].

The study had limitations. First, compliance with hand antisepsis and contact precautions was not monitored. However, as our study was a nonblind prospective one, the announcement of adherence monitoring could have influenced the staff attitude and possibly biased the results. Our aim was to evaluate A. baumannii acquisitions under the current infection-control practices in the ICU and not to estimate the level of staff compliance or the effectiveness of standard and contact precautions on the control of an outbreak.

Second, the workload for each ICU patient was not calculated. Instead, we evaluated an important number of patient-dependent factors, such as comorbidities, severity scores, duration of invasive procedures, and antibiotic exposure, which indirectly indicate the degree of nurse workloads.

\section{Conclusion}

An important impact of colonization pressure on multiresistant $A$. baumannii acquisition among ICU patients was demonstrated, and this finding probably adds new perspectives to the causative approach to sustained endemic situations. ICUs with similar problems should apply carriage-surveillance practices and implement additional infection-control measures immediately after identification of the first two carriers, rather than expect manifestation of infections or further spread of the pathogen. The factor Time, either as hospital days before ICU admission, or as antibiotic treatment-days and duration of mechanical ventilation during the ICU stay, was recognized as an independent risk factor for imported and acquired carriage, respectively. In settings in which carriage screening is unattainable because of increased cost and workload, infection-control measures should focus on, at least, the timely checking of patients with these risk factors. 
Our study suggests that colonization pressure and patient-related risk factors should be considered when multiresistant $A$. baumannii acquisition remains an unresolved issue in the ICU setting. Their consideration may trigger implementation of appropriate preventive measures such as better hand-hygiene compliance, reduction of health care worker movement between carriers and noncarriers, creation of cohorts of either patients or nursing staff, and limitation of the number of physicians entering patient rooms during rounds.

\section{Key messages}

- Multiresistant A. baumannii acquisition is correlated to colonization pressure and the total number of carriers per week. In endemic ICUs, surveillance practices and additional infection-control measures should be implemented immediately after identification of the first two carriers, rather than expecting further dissemination of the pathogen or infection manifestation.

- An important proportion of multiresistant A. baumannii carriers are admitted into the ICU from other wards of the hospital or other hospitals, creating a substantial reservoir for new acquisitions in ICUs in which the pathogen is endemic.

- Duration of hospitalization before the ICU is an important predictor of multiresistant $A$. baumannii carriage at ICU admission.

- Durations of antibiotic administration and mechanical ventilation in the ICU are independent risk factors for multiresistant $A$. baumannii acquisition.

\begin{abstract}
Abbreviations
APACHE II: Acute Physiologic and Chronic Health Evaluation; Cl: confidence interval; CVC: central venous catheter; ICU: intensive care unit; IQR: interquartile range; ODIN: Organ Dysfunctions and/or Infection; OR: odds ratio; SAPS II: Simplified Acute Physiology Score II.
\end{abstract}

\section{Acknowledgements}

We thank Theodoros Sakellariou for his technical assistance in developing figures and tables. We thank Wyeth Hellas for molecular analysis.

\section{Author details \\ 'Intensive Care Unit, "Papageorgiou" General Hospital, Periferiaki Odos, Thessaloniki, 56403, Greece. 'Intensive Care Unit, "Gennimatas" General Hospital, Ethnikis Aminas 41, Thessaloniki, 54635, Greece. ${ }^{3}$ Department of Clinical Microbiology, Centre Hospitalier Universitaire Bichat Claude-Bernard, Henri Huchard 46, Paris, 75018, France. ${ }^{4}$ Department of Hygiene and Epidemiology, Medical School, Aristotelian University of Thessaloniki, 54124, Greece. ${ }^{5}$ Department of Microbiology, "Papageorgiou" General Hospital, Periferiaki Odos, Thessaloniki, 56403, Greece. ${ }^{6}{ }^{\text {st }}$ Department of Internal Medicine, Medical School, Aristotle University of Thessaloniki, Stilponos Kyriakidi 1, 54636, Greece. ${ }^{7} 3^{\text {rd }}$ Department of Internal Medicine, Medical School, Aristotle University of Thessaloniki, Periferiaki Odos, 56403, Greece.}

\section{Authors' contributions}

$\mathrm{KA}$ and $\mathrm{DL}$ conceived the study and elaborated the data-analysis plan; KA, $D M, R R, P N$, and VK were responsible for data acquisition; KA and DL revised study data; $\mathrm{DL}$ and $\mathrm{ABH}$ were responsible for statistical analysis; $\mathrm{DL}, \mathrm{ABH}, \mathrm{KA}$, and RR performed data interpretation; KA and DL drafted the final manuscript; and KA and SM revised all presented data and reevaluated the manuscript. The corresponding author had full access to all the data in the study and had the final responsibility for the decision to submit for publication. All authors critically commented on the draft and approved the final version.

\section{Competing interests}

The authors declare that they have no competing interests.

Received: 27 February 2012 Revised: 24 April 2012

Accepted: 13 June 2012 Published: 13 June 2012

\section{References}

1. Peleg AY, Seifert H, Paterson DL: Acinetobacter baumannii: emergence of a successful pathogen. Clin Microbiol Rev 2008, 21:538-582.

2. Van Looveren M, Goossens H: Antimicrobial resistance of Acinetobacter spp. in Europe. Clin Microbiol Infect 2004, 10:684-704.

3. Garnacho-Montero J, Ortiz-Leyba C, Fernández-Hinojosa E, Aldabó-Pallás T, Cayuela A, Marquez-Vácaro JA, Garcia-Curiel A, Jiménez-Jiménez FJ: Acinetobacter baumannii ventilator-associated pneumonia: epidemiological and clinical findings. Intensive Care Med 2005, 31:649-655.

4. Cisneros JM, Rodríguez-Baño J: Nosocomial bacteremia due to Acinetobacter baumannii: epidemiology, clinical features and treatment. Clin Microbiol Infect 2002, 8:687-693.

5. Briggs S, Ellis-Pegler R, Raymond N, Thomas M, Wilkinson L: Gram-negative bacillary meningitis after cranial surgery or trauma in adults. Scand J Infect Dis 2004, 36:165-173.

6. Al Shirawi N, Memish ZA, Cherfan A, Al Shimemeri A: Post-neurosurgical meningitis due to multidrug-resistant Acinetobacter baumanii treated with intrathecal colistin: case report and review of the literature. $J$ Chemother 2006, 18:554-558.

7. Perez F, Hujer AM, Hujer KM, Decker BK, Rather PN, Bonomo RA: Global challenge of multidrug-resistant Acinetobacter baumannii. Antimicrob Agents Chemother 2007, 51:3471-3484.

8. Abbo A, Navon-Venezia S, Hammer-Muntz O, Krichali T, Siegman-Igra Y, Carmeli Y: Multidrug-resistant Acinetobacter baumannii. Emerg Infect Dis 2005, 11:22-29.

9. Villegas MV, Hartstein Al: Acinetobacter outbreaks, 1977-2000. Infect Control Hosp Epidemiol 2003, 24:284-295.

10. Ansaldi F, Canepa P, Bassetti M, Zancolli M, Molinari MP, Talamini A, Ginocchio F, Durando P, Mussap M, Orengo G, Viscoli C, Icardi G: Sequential outbreaks of multidrug-resistant Acinetobacter baumannii in intensive care units of a tertiary referral hospital in Italy: combined molecular approach for epidemiological investigation. J Hosp Infect 2011, 79:134-140.

11. Cristina ML, Spagnolo AM, Ottria G, Sartini M, Orlando P, Perdelli F, Galliera Hospital Group: Spread of multidrug carbapenem-resistant Acinetobacter baumannii in different wards of an Italian hospital. Am J Infect Control 2011, 39:790-794.

12. Markogiannakis A, Fildisis G, Tsiplakou S, Ikonomidis A, Koutsoukou A, Pournaras S, Manolis EN, Baltopoulos G, Tsakris A: Cross-transmission of multidrug-resistant Acinetobacter baumannii clonal strains causing episodes of sepsis in a trauma intensive care unit. Infect Control Hosp Epidemiol 2008, 29:410-417.

13. Pittet D, Hugonnet S, Harbarth S, Mourouga P, Sauvan V, Touveneau S: Effectiveness of a hospital-wide programme to improve compliance with hand hygiene. Lancet 2000, 356:1307-1312.

14. Larson EL, Early E, Cloonan P, Sugrue S, Parides M: An organizational climate intervention associated with increased handwashing and decreased nosocomial infections. Behav Med 2000, 26:14-22.

15. Vicca AF: Nursing staff workload as a determinant of methicillin-resistant Staphylococcus aureus spread in an adult intensive therapy unit. J Hosp Infect 1999, 43:109-113.

16. Nseir S, Grailles G, Soury-Lavergne A, Minacori F, Alves I, Durocher A: Accuracy of American Thoracic Society/Infectious Diseases Society of America criteria in predicting infection or colonization with multidrugresistant bacteria at intensive-care unit admission. Clin Microbiol Infect 2010, 16:902-908.

17. Playford EG, Craig JC, Iredell JR: Carbapenem-resistant Acinetobacter baumannii in intensive care unit patients: risk factors for acquisition, infection and their consequences. J Hosp Infect 2007, 65:204-211. 
18. Koeleman JG, Parlevliet GA, Dijkshoorn L, Savelkoul PH, VandenbrouckeGrauls CM: Nosocomial outbreak of multi-resistant Acinetobacter baumannii on a surgical ward: epidemiology and risk factors for acquisition. J Hosp Infect 1997, 37:113-123.

19. Bonten MJ, Slaughter S, Ambergen AW, Hayden MK, van Voorhis J, Nathan C, Weinstein RA: The role of "colonization pressure" in the spread of vancomycin-resistant enterococci: an important infection control variable. Arch Intern Med 1998, 158:1127-1132.

20. Merrer J, Santoli F, Appere de Vecchi C, Tran B, De Jonghe B, Outin H: "Colonization pressure" and risk of acquisition of methicillin-resistant Staphylococcus aureus in a medical intensive care unit. Infect Control Hosp Epidemiol 2000, 21:718-723.

21. D'Agata EM, Thayer $V$, Schaffner W: An outbreak of Acinetobacter baumannii: the importance of cross-transmission. Infect Control Hosp Epidemiol 2000, 21:588-591.

22. Garner JS: Guideline for isolation precautions in hospitals: The Hospital Infection Control Practices Advisory Committee. Infect Control Hosp Epidemiol 1996, 17:53-80

23. Siegel JD, Rhinehart E, Jackson M, Chiarello L, Health Care Infection Control Practices Advisory Committee: 2007 Guideline for Isolation Precautions: preventing transmission of infectious agents in health care settings. Am J Infect Control 2007, 35:S65-S164.

24. Garner JS, Jarvis WR, Emori TG, Horan TC, Hughes JM: CDC definitions for nosocomial infections. Am J Infect Control 1988, 16:128-140.

25. Horan TC, Andrus M, Dudeck MA: CDC/NHSN surveillance definition of health care-associated infection and criteria for specific types of infections in the acute care setting. Am J Infect Control 2008, 36:309-332.

26. Rosenthal VD, Bijie H, Maki DG, Mehta Y, Apisarnthanarak A, Medeiros EA, Leblebicioglu H, Fisher D, Alvarez-Moreno C, Khader IA, Del Rocío González Martínez M, Cuellar LE, Navoa-Ng JA, Abouqal R, Garcell HG, Mitrev Z, Pirez García MC, Hamdi A, Dueñas L, Cancel E, Gurskis V, Rasslan O, Ahmed A, Kanj SS, Ugalde OC, Mapp T, Raka L, Meng CY, Thu LT, Ghazal S, Gikas A, Narváez LP, Mejía N, Hadjieva N, Gamar Elanbya MO, Guzmán Siritt ME, Jayatilleke K, INICC members: International Nosocomial Infection Control Consortium (INICC) report, data summary of 36 countries, for 2004-2009. Am J Infect Control 2011

27. Peleg AY, Hooper DC: Hospital-acquired infections due to gram-negative bacteria. N Engl J Med 2010, 362:1804-1813.

28. Liu C, Bayer A, Cosgrove SE, Daum RS, Fridkin SK, Gorwitz RJ, Kaplan SL, Karchmer AW, Levine DP, Murray BE, J Rybak M, Talan DA, Chambers HF: Clinical practice guidelines by the infectious diseases society of america for the treatment of methicillin-resistant Staphylococcus aureus infections in adults and children: executive summary. Clin Infect Dis 2011, 52:285-292.

29. Rello J, Ulldemolins M, Lisboa T, Koulenti D, Mañez R, Martin-Loeches I, De Waele JJ, Putensen C, Guven M, Deja M, Diaz E, EU-VAP/CAP Study Group: Determinants of prescription and choice of empirical therapy for hospital-acquired and ventilator-associated pneumonia. Eur Respir J 2011, 37:1332-1339.

30. Mermel LA, Allon M, Bouza E, Craven DE, Flynn P, O'Grady NP, Raad II, Rijnders BJ, Sherertz RJ, Warren DK: Clinical practice guidelines for the diagnosis and management of intravascular catheter-related infection: 2009 Update by the Infectious Diseases Society of America. Clin Infect Dis 2009, 49:1-45

31. Ewig S: Nosocomial pneumonia: de-escalation is what matters. Lancet Infect Dis 2011, 11:155-157.

32. Joffe AR, Muscedere J, Marshall JC, Su Y, Heyland DK: The safety of targeted antibiotic therapy for ventilator-associated pneumonia: a multicenter observational study. J Crit Care 2008, 23:82-90.

33. McCabe WR, Jackson GG: Gram negative bacteremia: I. Etiology and ecology. Arch Intern Med 1962, 110:845-847.

34. Knaus WA, Zimmerman JE, Wagner DP, Draper EA, Lawrence DE: APACHEacute physiology and chronic health evaluation: a physiologically based classification system. Crit Care Med 1981, 9:591-597.

35. Le Gall JR, Lemeshow S, Saulnier F: A new Simplified Acute Physiology Score (SAPS II) based on a European/North American multicenter study. JAMA 1993, 270:2957-2963.

36. Fagon JY, Chastre J, Novara A, Medioni P, Gibert C: Characterization of intensive care unit patients using a model based on the presence or absence of organ dysfunctions and/or infection: the ODIN model. Intensive Care Med 1993, 19:137-144.
37. Berlau J, Aucken H, Malnick H, Pitt T: Distribution of Acinetobacter species on skin of healthy humans. Eur J Clin Microbiol Infect Dis 1999, 18:179-183.

38. NCCLS: Performance Standards for Antimicrobial Susceptibility Testing; 15th Informational Supplement. 2005, 10, Document M100-S15.

39. Snelling AM, Gerner-Smidt P, Hawkey PM, Heritage J, Parnell P, Porter C, Bodenham AR, Inglis T: Validation of use of whole-cell repetitive extragenic palindromic sequence-based PCR (REP-PCR) for typing strains belonging to the Acinetobacter calcoaceticus-Acinetobacter baumannii complex and application of the method to the investigation of a hospital outbreak. J Clin Microbiol 1996, 34:1193-1202.

40. Bagley SA, White $H$, Colomb BA: Logistic regression in the medical literature: standards for use and reporting, with particular attention to one medical domain. J Clin Epidemiol 2001, 54:979-985.

41. Corbella X, Montero A, Pujol M, Dominguez MA, Ayats J, Argerich MJ, Garrigosa F, Ariza J, Gudiol F: Emergence and rapid spread of carbapenem resistance during a large and sustained hospital outbreak of multiresistant Acinetobacter baumannii. J Clin Microbiol 2000, 38:4086-4095.

42. Schwaber MJ, Lev B, Israeli A, Solter E, Smollan G, Rubinovitch B, Shalit I, Carmeli Y, Israel Carbapenem-Resistant Enterobacteriaceae Working Group: Containment of a country-wide outbreak of carbapenem-resistant Klebsiella pneumoniae in Israeli hospitals via a nationally implemented intervention. Clin Infect Dis 2011, 52:1-8.

43. Dancer SJ, Coyne M, Speekenbrink A, Samavedam S, Kennedy J, Wallace PG: MRSA acquisition in an intensive care unit. Am J Infect Control 2006, 34:10-17.

44. Kaier K, Meyer E, Dettenkofer M, Frank U: Epidemiology meets econometrics: using time-series analysis to observe the impact of bed occupancy rates on the spread of multidrug-resistant bacteria. $J$ Hosp Infect 2010, 76:108-113.

45. Azim A, Dwivedi M, Rao PB, Baronia AK, Singh RK, Prasad KN, Poddar B, Mishra A, Gurjar M, Dhole TN: Epidemiology of bacterial colonization at intensive care unit admission with emphasis on extended-spectrum beta-lactamase- and metallo-beta-lactamase-producing Gram-negative bacteria: an Indian experience. J Med Microbiol 2010, 59:955-960.

46. del Mar Tomas M, Cartelle M, Pertega S, Beceiro A, Llinares P, Canle D, Molina F, Villanueva R, Cisneros JM, Bou G: Hospital outbreak caused by a carbapenem-resistant strain of Acinetobacter baumannii: patient prognosis and risk-factors for colonisation and infection. Clin Microbiol Infect 2005, 11:540-546.

47. Tacconelli E, De Angelis G, Cataldo MA, Pozzi E, Cauda R: Does antibiotic exposure increase the risk of methicillin-resistant Staphylococcus aureus (MRSA) isolation? A systematic review and meta-analysis. J Antimicrob Chemother 2008, 61:26-38.

48. Dent LL, Marshall DR, Pratap S, Hulette RB: Multidrug resistant Acinetobacter baumannii: a descriptive study in a city hospital. BMC Infect Dis 2010, 10:196.

49. Nseir S, Blazejewski C, Lubret R, Wallet F, Courcol R, Durocher A: Risk of acquiring multidrug-resistant Gram-negative bacilli from prior room occupants in the intensive care unit. Clin Microbiol Infect 2011, 17:1201-1208.

50. Fillaux J, Dubouix A, Conil JM, Laguerre J, Marty N: Retrospective analysis of multidrug-resistant Acinetobacter baumannii strains isolated during a 4-year period in a university hospital. Infect Control Hosp Epidemiol 2006, 27:647-653.

doi:10.1186/cc11383

Cite this article as: Arvaniti et al:: The importance of colonization pressure in multiresistant Acinetobacter baumannii acquisition in a Greek intensive care unit. Critical Care 2012 16:R102. 